\title{
«A muscles de gegant»: els incunables del Flos sanctorum català, entre la tradició i la revisió ${ }^{1}$
}

\section{Hèctor Càmara-Sempere}

Universitat d'Alacant

hector.camara@ua.es

Recepció: 27/01/2017, Acceptació: 27/06/2017, Publicació: 22/12/2017

\begin{abstract}
Resum
Els dos incunables que transmeten la traducció catalana de la Legenda aurea de Iacopo da Varazze (un de 1494 i un altre sense datar, però coetani) arrepleguen una tradició textual que es retrotrau a finals del segle XIII, la qual s'ha conservada en cinc manuscrits complets i en multitud de textos fragmentaris. A pesar que encara no s'ha establert un stemma que permeta esbrinar les relacions entre aquests testimonis, sí que podem asseverar que els incunables reprodueixen aquesta tradició manuscrita i ajuden a transvasar-la a les edicions catalanes del segle Xvi. Però, també és cert que introdueixen modificacions, algunes de les quals tenen a veure amb una revisió del text català. Amb aquest treball pretenem fer un tast d'aquestes innovacions i comparar-les amb la tradició anterior i posterior per estudiar les motivacions que hi ha al darrere d'aquests canvis.
\end{abstract}

Paraules clau

Legenda aurea; Jacobus de Voragine; Flos sanctorum; hagiografia; català

\begin{abstract}
"A muscles de gegant": The incunabula of the Catalan Flos Sanctorum, between tradition and revision

The two incunabula that transmit the Catalan translation of the Legenda aurea by Jacobus de Voragine (while one of them was published in 1494, the other one is
\end{abstract}

1. Aquest treball s'emmarca en el projecte La literatura hagiográfica catalana, entre el manuscrito y la imprenta (FFI2013-43927-P) del Ministeri d'Economia i Competitivitat. 
undated but is known to be contemporary) belong to a textual tradition that was initiated during the last part of the thirteenth century and which has been preserved in five complete manuscripts and many fragmentary texts. Although a stemma that allows scholars to discover the connection between these testimonies has not yet been established, we assert that both incunabula follow the tradition based on those five manuscripts and, also, that both contribute to its transmission into the Catalan editions produced in the sixteenth century. Then again, it is true that a number of modifications are included in these incunabula, some of which are indebted to a revision of the Catalan text. With this paper, we intend to offer an overview of these innovations and compare them with both earlier and later traditions in order to study these changes.

\section{Keywords}

Legenda aurea, Jacobus de Voragine, Flos sanctorum, hagiography, Catalan

\section{Proemi: la Legenda aurea en català}

La Legenda aurea és un gegant de proporcions mastodòntiques. No tant per l'extensió — hi ha obres medievals molt més vastes—, sinó per la còpia i difusió de les quals fou objecte, cosa que la convertí en una de les obres amb més fortuna, si no la que més després de les Sagrades Escriptures, al llarg de la baixa edat mitjana. El dominic genovés Iacopo da Varazze (1226/1230-1298) potser no era massa conscient de l'èxit quan, cap al 1260, començà a redactar un nou llegendari abreujat, gènere que en aquell moment tenia èxit dins del seu orde i que consistia a reelaborar en compendis tot el material que, durant pràcticament un mil.lenni, s'havia transmés a través de les passions i les vides de sants. En aquest sentit, arreplega en 178 capítols els sants i les festes principals del calendari litúrgic romà en una estructura cíclica que permetia incorporar capítols apòcrifs com més es difonia, amb l'objectiu de proporcionar material per als sermons dels seus companys de regla. És cert que tenia antecedents notables en les recopilacions de Jean de Mailly (Abbreviatio in gestis sanctorum, la primera versió de la qual és de 1228-1230) i Bartolomeo da Trento (Liber epilogorum in gesta sanctorum, de 
1245), cap de les quals assolí l'èxit de la de Varazze, amb un miler de manuscrits conservats arreu d'Europa. ${ }^{2}$ I açò gràcies al fet que ben aviat el públic potencial al qual anava adreçada l'obra era major del previst, ja que s'hi incorporaren uns altres tipus de lectors, no necessàriament amb coneixements de llatí, que feren del llegendari una obra adequada per a promoure la devoció personal. Açò, evidentment, incentivà la traducció a diverses llengües vernacles, entre les primeres de les quals es troba el català, abans d'acabar el Dos-cents. ${ }^{3}$

A banda de les notícies que ens han pervingut de la presència de Flores sanctorum en biblioteques eclesiàstiques, reials i nobiliàries arreu dels territoris catalanoparlants i, fins i tot, de la recomanació de la lectura per part d'autors com Ramon Llull o Arnau de Vilanova, en conservem cinc testimonis complets: ${ }^{4}$

- Manuscrit P. El testimoni més conegut dels conservats i el que ha suscitat més interés és el ms. esp. 44 de la Biblioteca Nacional de França, conegut amb el nom de Vides de sants rosselloneses i publicat per Coromines, Maneikis-Kniazzeh i Neugaard (Voragine 1977). La còpia es pot datar de finals del segle XIII o començaments del XIV. ${ }^{5}$

- Manuscrit E. Un dels manuscrits més interessants, encara inèdit, és el conservat a la Biblioteca del Monestir de l'Escorial amb la signatura N-III-5 i el títol de Flos sanctorum en cathalà a les guardes, de mà posterior. Aquesta còpia es podria datar de mitjan segle XIV.

- Manuscrit M. A la Reial Acadèmia de la Història de Madrid, amb la signatura cod. LxxxviII, hi ha desat un altre manuscrit català de la $L e-$ genda aurea $\mathrm{amb}$ el títol, de mà posterior, Vidas y milagros de diferentes santos en un libro de foleo, copiat en el segle XIV.

2. Pel que fa als llegendaris abreujats i a l'obra de Varazze, són imprescindibles els treballs de Maggioni (especialment, 1995 i 2012).

3. Coromines explica que la traducció catalana fou possible gràcies a les relacions directes establertes «entre el monestir de Cuixà i els centres religiosos del nord d'Itàlia, contactes provats per documents concrets fins a una data posterior a la de la traducció, i consistents en part, segons aquella documentació, en aportacions italianes, que comprenien segons sembla textos o llibres» (Voragine 1977: I, XXII); i Maneikis-Kniazzeh, després de donar a conéixer algunes dades que demostren aquesta relació, conclou: «Cuixà, amb el seu renom com a lloc sant -es diu que el 970 fou descoberta prop del monestir la tomba de sant Hilari-i amb la seva importància com a centre literari, fou probablement el monestir que produí la traducció catalana de Voragine, i és encara més probable que fou el lloc on es va copiar el manuscrit $P_{»}$ (Voragine 1977: III, 505). També s'ha plantejat la possibilitat de l'existència de més d'una versió catalana de la Legenda aurea: «Si bé es troba una relació estreta entre els textos difosos per la impremta i alguns dels testimonis més antics, com ara el manuscrit de París, no tots els exemplars manuscrits transmeten la mateixa traducció, de manera que podem parlar de més d'una traducció de les vides de Voràgine en català» (Sabaté-Soriano-Avenoza 2012: 38). En tot cas, el que sí que podem afirmar és que els cinc manuscrits complets formen part d'una mateixa tradició, encara que caldria estudiar vida per vida per veure les diferències i les possibles interpolacions.

4. Per a una informació més detallada d'aquestes notícies i per a la descripció ampliada dels diversos testimonis, vid. Càmara (2013: XXXIV-XXXIx).

5. Pel que fa a la datació dels manuscrits, consulteu el treball de García Sempere (2015). 
- Manuscrit B. Un altre manuscrit és el que es conserva a la Biblioteca de la Universitat de Barcelona (núm. 713), que fou aprofitat per a anotar les variants respecte del manuscrit de París en l'edició de 1977, amb el qual sembla tenir una certa vinculació. Aquest testimoni, amb el títol de Flos sanctorum en català, afegit per una mà posterior, es data de finals del segle XIv.

- Manuscrit V. Un altre dels volums que contenen la traducció catalana de l'obra de Varazze és el conservat a l'Arxiu Capitular de Vic (sig. c. 174 L), publicat per Nolasc Rebull (Voràgine 1976) i que duu al llom el nom de Legenda aurea. Encara que hi ha diverses opinions, sembla que aquesta còpia es pot datar de finals del segle XIV o començaments del XV.

A aquests cinc manuscrits, s'hi ha d'afegir un conjunt de testimonis parcials i fragmentaris i, fins i tot, d'extractes de transmissió autònoma i independent que completen la tradició catalana de la Legenda aurea, que no descriurem ara. ${ }^{6}$

A finals del segle $\mathrm{xv}$, amb l'arribada de la impremta a les nostres terres, hi hagué una major difusió d'aquelles obres que ja havien obtingut èxit en la transmissió manuscrita dels segles anteriors. La traducció de la Legenda aurea, com el cas d'altres obres de caire devocional, començà a imprimir-se des dels primers moments, sempre amb el nom de Flos sanctorum. En català en conservem dos incunables (el Flos sanctorum romançat, editat per Johan Rossenbach, Barcelona, 1494; i un altre d'incomplet, que podem datar d'entre el 1490 i el 1496) ${ }^{7}$ i sis edicions cinccentistes: Jorge Costilla, València, 1514 (Biblioteca de la Universitat de València, R 1/315; Biblioteca de Catalunya, 10-VI-19); Carles Amorós, Barcelona, 1519-1520 (Biblioteca Lambert Mata de Ripoll, r. 456); Carles Amorós, Barcelona, 1524 (Biblioteca de la Universitat de Barcelona, B-58/2/12; Biblioteca de Catalunya, 10-VI-18); un altre acèfal, anterior a 1546 (Biblioteca Lambert Mata de Ripoll, r. 206); Carles Amorós, Barcelona, 1547, reimpressió de l'edició de 1524 (Biblioteca de Catalunya, 10-VI-17); Jaume Cendrat, Barcelona, 1575 (Biblioteca Nacional de Madrid, R-12104).

En tota aquesta llarga transmissió del text de Varazze, els incunables adquereixen una posició central des del punt de vista ecdòtic, ja que assumeixen el text de la traducció primigènia, amb els canvis i els afegitons que corresponen a qualsevol procés de còpia, i introdueixen innovacions que traspassen a les edicions del segle XVI. En aquest sentit, tal com indica el símil del títol, els impresos quatrecentistes del Flos sanctorum, en l'afortunada expressió del filòsof Bernat de Chartres (de començaments del segle XII), que posteriorment reaprofità Isaac Newton, són nans que s'alcen en els muscles d'un gegant com la Legenda aurea en català (no debades, l'antiguitat del text i l'extensió de l'obra traduïda la converteixen en una fita primerenca d'aquesta llengua), capaços de transmetre-la a una nova tradició i

6. Per a una descripció d'aquests testimonis, vid. Avenoza-García Sempere (2012: 53-57).

7. En podeu trobar una descripció codicològica detallada en Càmara (2013: XLII-XLVI). 
deixar-hi una empremta encara per estudiar a fons. És aquesta herència manuscrita i aquest traspàs imprés des del punt de vista dels dos incunables l'objectiu del treball que presentem. Què hi ha de tradició i que hi ha d'innovació en les primeres edicions de la traducció de la Legenda aurea de Iacopo da Varazze al català? La resposta a aquesta pregunta pot ajudar a entendre alguns dels trets característics d'aquesta versió en vernacle de l'obra del dominic genovés.

\section{El Flos sanctoum romançat, un pont entre la tradició manuscrita i la revisió impresa}

Des del punt de vista hagiogràfic, aquest símil de Bernat de Chartres que fem servir és anàleg a la història de sant Cristòfol. Amb la idea fixa de servir el senyor més poderós, el gegant Reprovat, que així es deia abans de la conversió, passà per diferents reis i, fins i tot, pel Dimoni fins que un ermità li obrí els ulls a Crist i decidí dedicar-se a ajudar els necessitats a travessar un riu d'una riba a l'altra, faena que li permetia consagrar la seua vida al seu senyor. Un dia se li presentà un nen que volia anar a l'altre costat, se'l posà als muscles i, segons anava avançant, li semblava que pesava com més va, més. Al cap i a la fi, sobre les espatles carregava el pes del món. I aquesta funció de crear ponts amb l'ajuda d'un gegant com sant Cristòfol, fins i tot, s'adiu més, metafòricament, al transvasament que es produeix entre la tradició manuscrita de la traducció catalana de la Legenda aurea $\mathrm{i}$ les edicions impreses mitjançant els dos incunables, i que podem esbrinar a través de tres tipus d'exemples: els capítols afegits a l'obra original de Varazze, els canvis en l'estructura organitzativa ideada per l'autor i les revisions que incorporen les edicions de 1494 i 1490-1496, que anomenaré $\mathrm{I}^{\mathrm{I}}$ i $\mathrm{I}^{2}$ respectivament. ${ }^{8}$

\section{Els capítols afegits: el cicle litúrgic es completa}

Gràcies a l'estudi ecdòtic de Maggioni (1995),, sabem que la Legenda aurea comptà almenys amb dues redaccions. La primera, que no es pot datar amb exactitud, la podríem situar cap al 1260, quan Iacopo da Varazze era prior d'Asti i encara no havia obtingut cap càrrec de rellevància dins de l'orde de Predicadors. Posteriorment, anà revisant-la, corregint-la i afegint-ne noves dades fins a la seua mort el 1298, moment en què podem datar la versió definitiva de l'obra, ja com a arquebisbe de Gènova. Encara que parlem, doncs, de dues versions, la confecció de l'obra es pot entendre com un work in progress que es desenvolupà al llarg de la seua vida i del

8. Aquesta nomenclatura respon a l'edició crítica que presentàrem en la tesi (Càmara 2013). A l'imprés de 1494 correspon l'abreviatura $\mathrm{I}^{1}$, ja que es tracta del text base, més complet i extens que el de 1494-1496.

9. De manera més resumida, Maggioni ha tractat el tema en altres treballs, vid. per exemple la introducció a la seua traducció a l'italià de l'obra (Varazze 2007: XXI-XXIX). 
qual coneixem els diferents progressos. ${ }^{10}$ Açò, evidentment, n'afectà la transmissió en llatí i en les diferents llengües en les quals es traduí.

La Legenda aurea, com s'ha dit adés, ordena el contingut a partir del calendari litúrgic cristià, que s'inicia en l'Advent. En el pròleg, Varazze hi explica la divisió del temps eclesiàstic al llarg de l'any, base simbòlica damunt de la qual construeix la macroestructura que organitza les diverses vides i festivitats de l'obra: temps de desviació, temps de renovació, temps de reconciliació i temps de peregrinació. Certament, aquesta és una disposició enginyosa que els llegendaris abreujats aprofiten, ja que permet una reactualització temporal de l'obra de forma cíclica i continuada. Tanmateix, aquesta estructura marc no és cap innovació, es feia servir des d'antic en martirologis, himnaris o breviaris. La novetat està a fer confluir en aquestes obres un munt considerable de referents i materials anteriors organitzats en un sistema de facil consulta per als predicadors, en primera instància, i per als lectors devots, en segona.

Iacopo da Varazze escriu 178 capítols, dels quals 23 estan dedicats a celebracions litúrgiques relacionades amb la vida de Crist o de Maria (Anunciació, Advent, Nativitat, Circumcisió, Epifania, Purificació, Passió, Resurrecció, Assumpció, etc.), al culte de la Creu i a festes eclesiàstiques (Tots Sants, Ànimes, Dedicació de l'Església, etc.), i la resta, a festes del santoral romà més generalitzat, repartides majoritàriament entre apòstols, màrtirs, verges i confessors del segle I al vir i alguns sants del XIII, amb una llacuna de cinc segles que reflecteix la tendència arcaïtzant en la selecció. Lautor es decanta per un model de santedat que privilegia la cerca del martiri i, per aquest motiu, la major part de vides de sants que arreplega corresponen a morts per la fe dels primers segles del cristianisme. Fins i tot, entre els sants més acostats cronològicament a l'autor, hi ha aquesta preferència, com són els casos de sant Tomàs de Canterbury o de sant Pere Màrtir (Boureau 1984: 38-39).

Lèxit de la Legenda aurea, juntament amb la macroestructura in circulum anni que presenta, féu que en les còpies i traduccions de l'obra s'incorporaren des de ben prompte vides afegides anònimes que seguien l'estil abreujat del gènere i que acostaven els diferents testimonis a la devoció local. D’aquesta manera, una de les característiques que havia ajudat a la difusió arreu d'Europa d'aquest llegendari, la universalitat del calendari litúrgic, estava al darrere de la creació d'un santoral local divers que s’afegia a l'ordenació de l'obra original, la completava i l'adaptava per als fidels. Aquestes vides suplementàries, al seu torn, ajudaren a difondre dins dels seus territoris cada una de les tradicions manuscrites que s'anaven creant.

10. En paraules de Maggioni: «Secondo la nostra ipotesi esistono almeno due redazioni della Legenda aurea che sono da considerarsi d'autore. Il passaggio da una redazione all'altra sembra essersi svolto progressivamente, man mano che l'autore veniva a conoscenza di dati o di exempla che riteneva potessero essere utilmente inseriti nella sua opera» (1995: 102). Aquest autor anomena LA1 al primer estat de redacció i LA2, al segon. 
En el cas la de traducció catalana, i al llarg de la transmissió baixmedieval, $s^{\prime}$ incoporen diverses vides que arriben fins als incunables. En aquest sentit, $\mathrm{I}^{1} \mathrm{i}$ $\mathrm{I}^{2}$ arrepleguen un conjunt de capítols afegits que no trobem en cap de les redaccions de l'obra de Varazze i que provenen de la tradició manuscrita catalana:

- La vida de sancta Bàrbara (IV): B, V ${ }^{11}$

- La vida de sancta Coloma (xv): V

- La vida de sanct Brandà (XIX): E, V

- La vida de sancta Eulària verge (XXXIX) i La translatió de sancta Eulària $(\mathrm{xL})$ : $\mathrm{B}, \mathrm{E}, \mathrm{V}$

- La vida de sancta Quitèria (LXXIII): E, V

- La vida de sanct Guillem (LXXV): V

- La vida de sanct Anthoni de Pàdua (LXxx): V

- Sanct Feliu e sanct Cugat màrtirs (c): E, V

- La vida de sanct Feliu de Gerona (CVI): P, B, E, M, ${ }^{12} \mathrm{~V}$

- La vida de sancta Clara (CXvI): V

- La vida de sancta Tecla (CXLII): V

- La vida de sanct Narcís de Gerona (CLVI): P, B, V

- La vida de sanct Pons (CLXXXII): E

A banda d'aquestes vides, amb les quals s'actualitza el calendari amb devocions pròpies dels territoris catalanoparlants (com ara, santa Eulàlia, sant Feliu, santa Tecla o sant Narcís) o amb sants que acabaren popularitzant-se, però que no trobem en la Legenda aurea (és el cas, per exemple, de santa Clara o sant Antoni de Pàdua), $\mathrm{I}^{1}$ incorpora alguns capítols inexistents en els manuscrits precedents conservats:

- La vida de sanct Pafunci (CLXXVII)

- La vida de sanct Pafunci hermità (CLXXviII) $)^{13}$

- La vida de sancta Susanna (CLXXXIII)

- La hystòria de la gloriosa verge sancta Praxedis, cors sanct de la ciutat de Mallorques (CLXXXIX)

- La vida de sanct Bernardi (CXc)

- La vida de la benventurada sancta Katherina de Sena (CXCI ${ }^{14}$

11. Entre parèntesis i en xifres romanes, s’indica el número del capítol en $\mathrm{I}^{1}$; les lletres majúscules fan referència als manuscrits en què també trobem la vida afegida.

12. Aquest manuscrit no incorpora cap capítol afegit, llevat d'aquest, fet que caldria estudiar més detingudament.

13. Encara que l'epígraf siga semblant al de la vida anterior, aquesta està dedicada a santa Eufrosina.

14. És interessant comprovar com la major part dels capítols que $I^{1}$ aporta i suma a la tradició anterior se situen al final de l'obra com un suplement que encara no ha entrat a formar part de l'estructura cíclica. 
I l'altre incunable $\left(\mathrm{I}^{2}\right)$, a més a més, hi afegeix de collita pròpia:

- De sant Amador ${ }^{15}$

- De santa Brígida

- De sanct Vicens Ferrer

- De sant Onoffre

- La vida de sant Roch

Aquests nous capítols que apareixen en els primers impresos catalans del Flos sanctorum, a diferència dels que provenen de la tradició manuscrita, incorporen també la modernització del santoral amb algunes vides que superen la cronologia de l'obra de lacopo da Varazze (com ocorre amb santa Caterina de Siena, sant Vicent Ferrer o sant Roc). Tots aquests capítols addicionals dels incunables es traspassen, sense anar més lluny, a l'edició de 1514, que els arreplega tots. En aquest sentit, $\mathrm{I}^{1} \mathrm{i}$ $\mathrm{I}^{2}$ afegeixen nou material textual desconegut amb anterioritat que acaba per fixar-se posteriorment, com demostra l'aparició en la primera publicació cinccentista.

\section{Una obra amb una estructura que es desborda}

En l'organització cronològica dels capítols al llarg del cicle litúrgic anual trobem un dels trets que més diferencia els incunables respecte de la Legenda aurea, ja que n'hi ha dèsset desplaçats del lloc que haurien d'ocupar segons la data de la festivitat, que Varazze segueix fidelment. En alguns casos, podem trobar alguna explicació, com ara en la vida dels set germans dorments, que apareix, per analogia, darrere de la dels set germans; la de santa Marta, darrere del de la seua germana santa Maria Magdalena; o el de sant Eustaqui, la celebració del qual l'autor situa l'1 de novembre i els incunables el 20 de setembre. ${ }^{16}$ En aquests exemples, per contra, els manuscrits P, B, E, M i V segueixen l'ordre establert en la Legenda aurea, cosa que no fa l'edició de 1514, que reprodueix la disposició dels incunables.

D'altra banda, observem també canvis que creen un conjunt de vides amb una temàtica determinada. En aquest sentit, el grup de capítols dedicats als Pares del desert amb què Varazze tanca l'obra es veu completat amb el desplaçament i la inclusió d'altres sants i santes penitents afins. ${ }^{17} \mathrm{~A}$ banda d'incorporar un

15. També trobem aquesta vida en el manuscrit V; però hem decidit posar-la en aquest llistat perquè quedaran més clares les diferències entre els incunables.

16. La data de celebració primigènia era l'1 de novembre i, posteriorment, quan s'instituí la festivitat de Tots Sants, el 2. A partir del segle viII, apareix ja en alguns calendaris el 20 de setembre, data que finalment esdevingué universal. La Legenda aurea, doncs, es decanta per col-locar la vida en la data més antiga i, en canvi, el Flos sanctorum per situar-la en la més moderna i que devia ser en la qual tenia lloc la commemoració a finals ja del segle xv.

17. En paraules de Maggioni: «Iacopo costituisce alla fine della Legenda aurea, in corrispondenza della conclusione dell'anno liturgico, una sorta di appendice senza alcun rapporto con il calendario. C’è sicuramente una relazione con il xvi libro dello Speculum Historiale di Vincenzo di Beauvais, in cui sono stati raccolti i santi di cui non si avevano notizie esatte riguardo all'epoca 
capítol dedicat a sant Pafnuci, es recull una vida dedicada a santa Eufrosina, que s'uneix a la de santa Teodora, santa Tais i santa Pelàgia, que es mouen a la part final, amb la qual cosa es crea un grup femení com a contrapunt i complement al conjunt de capítols extrets de les Vitae Patrum. Algunes d'aquestes dones, a més a més, coincideixen, com si es tractara d'una mena de subgrup, en el transvestisme masculí, que els serveix per a fugir del món i perseverar en el seu ascetisme, com és el cas de santa Eufrosina, santa Teodora o santa Pelàgia. ${ }^{18}$ Aquesta disposició es transvasa de nou a l'edició de 1514, que la copia.

\begin{tabular}{l|l}
\hline La vida de sanct Pastor & LA 171 \\
\hline La vida de sanct Johan abat & LA 172 \\
\hline La vida de sanct Moysés abat & LA 173 \\
\hline La vida de sanct Arseni & LA 174 \\
\hline La vida de sanct Agathon abat & LA 175 \\
\hline La vida de sanct Pafunci $[s i c]$ & $\begin{array}{l}\text { Varazze no inclou una vida dedicada a sant Pafnuci en } \\
\text { la LA }\end{array}$ \\
\hline La vida de sanct Pafunci $[s i c]$ hermità & $\begin{array}{l}\text { Encara que l'epígraf esmente sant Pafnuci ermità, del } \\
\text { qual ha tractat la vida anterior, el capítol narra la vida } \\
\text { de santa Eufrosina. Varazze no inclou una vida dedicada } \\
\text { a santa Eufrosina }\end{array}$ \\
\hline La vida de sancta Theodora & LA 88 \\
\hline La vida de sancta Thaycís & LA 147 \\
\hline La vida de sancta Pelàgia & LA 146 \\
\hline
\end{tabular}

Cal afegir-hi, endemés, una omissió gens anecdòtica en $\mathrm{I}^{2}$, que no arreplega un dels capítols fonamentals dins del cicle litúrgic, el de la Passió, tret que es trasllada a la resta d'edicions del xvi. Aquest buit sorprenent se supleix en els impresos de 1524, 1547 i $1576 \mathrm{amb}$ un suplement afegit de textos a l'inici dels volums, en el qual trobem alguns escrits apòcrifs (com ara, la carta de Lèntul que descriu la fesomia de Crist) o un fragment de Gerson.

Tot plegat ens indica que, encara que el cicle litúrgic que organitza l'obra és una estructura amb un ordre predeterminat (amb la qual cosa, qualsevol afegit, com hem vist en l'apartat anterior, té un lloc específic segons la data de celebració), això no obsta perquè hi haja petites alteracions que modifiquen l'ús devocional de l'obra.

della loro vita, gran parte dei quali venivano proprio dalla tradizione delle Vitae Patrum» (Varazze 2007: 1705).

18. No són els únics casos de transvestisme femení que hi ha a la Legenda aurea. És el cas, per exemple, de la vida de santa Marina, que no ha sigut desplaçada fins al final de l'obra, com sí que ha passat amb santa Teodora o amb santa Pelàgia. 


\section{A la cerca del text perdut: les revisions}

A banda dels suplements afegits i dels canvis que es produeixen en la disposició de les diverses parts de l'obra, també trobem en els incunables modificacions que afecten el contingut dels capítols i que suposen una revisió conscient del text que presenta la Legenda aurea o del que ha transmés la tradició catalana manuscrita. ${ }^{19}$ Concretem aquestes innovacions, pel que fa a la fidelitat amb l'obra de Iacopo da Varazze, en la substitució completa del contingut d'alguns dels capítols; i, quant al tractament de la versió catalana que ha pervingut als incunables, en les correccions que hi introdueixen a partir d'una font llatina del llegendari, encara que no sistemàtiques. ${ }^{20}$

1) Vides divergents. En unes poques vides trobem que, a pesar d'estar incloses en la Legenda aura, els incunables catalans s'allunyen d'aquesta font i transmeten un text diferent. El cas més curiós és el del capítol dedicat a sant Pau Ermità, en què se substitueix l'abreujament que ofereix el llegendari de Varazze per una traducció completa de la mateixa font que fa servir el dominic: la Vita Pauli de sant Jeroni. En la vida de santa Marina verge observem que es tracta d'una versió diferent de la continguda en la Legenda aurea, ja que sembla que segueix aquesta narració, però la història està més desenvolupada i conté més detalls. ${ }^{21} \mathrm{El}$ cas de la vida de sant Pastor és diferent d'aquests dos. És cert que el contingut hi apareix més sintetitzat, però la característica que fa que es distancie de la versió de Varazze és que es presenta un altre ordre dels episodis interns. De tota manera, cal deixar ben clar que la dependència de contingut amb la font és clara.

En tots aquests exemples l'edició de 1514 coincideix amb els incunables; en canvi, els manuscrits P, B, E, M ${ }^{22}$ i V són fidels a la Legenda aurea, fet que constata que la innovació és un tret específic dels impresos.

2) Revisions esporàdiques. Al llarg del text dels incunables del Flos sanctorum podem resseguir diverses correccions de la traducció que difonen els manuscrits anteriors, en les quals s'aporten solucions que, d'alguna manera, s'acosten més

19. El nostre objectiu no és oferir una llista exhaustiva de revisions, cosa per a la qual caldria oferir una col-lació sistemàtica del text dels incunables amb els manuscrits anteriors i amb la font llatina, sinó un conjunt d'exemples que demostren l'existència d'aquests canvis.

20. Fem servir l'edició crítica que Maggioni fa de la Legenda aurea (Varazze 2007) per a veure les diferències amb els incunables catalans, encara que açò sempre és limitat. Com ens ha fet veure el mateix Maggioni, el seu treball ha consistit a elaborar una versió ideal reconstruïda de la segona redacció (LA2) d'una obra de transmissió excessivament complexa. Sense conèixer els testimonis llatins locals, tasca que sobrepassa de molt aquest treball, no podem arribar a assegurar d'on parteixen les innovacions.

21. Aquesta vida també apareix desplaçada fins al lloc que hauria d'ocupar santa Teodora (10 de juliol), al seu torn traslladada al grup dels Pares del desert. La data de celebració és el 18 de juny, però la convergència en l'argument de la vida entre santa Marina i santa Teodora potser està al darrere del desplaçament en el calendari que presenta el Flos sanctorum.

22. No conté la vida de sant Pastor, ja que la part final del testimoni no s'ha conservat. 
a la font llatina o, si ho volem dir d'una manera més matisada, a una altra opció dins de la complexa transmissió de la Legenda aurea. No és un fet ni de lluny sistemàtic, però és cert que el curador del contingut que arreplega $\mathrm{I}^{1}{ }_{\text {i }} \mathrm{I}^{2}$ consulta algun testimoni de l'obra de Varazze que li permet ampliar el text sense eixir-se realment de la tradició relacionada amb aquest llegendari. ${ }^{23}$ Els canvis introduïts, com calia esperar, es transvasen a l'edició de 1514, que incorpora la modificació.

Trobem diversos tipus d'exemples. ${ }^{24}$ En primer lloc, les revisions que completen fragments tot aprofitant la informació que aporta la versió de la Legenda aurea que es fa servir per a la col-lació amb el text català. D'aquesta manera, en la vida de sant Pere es diu:

\begin{tabular}{|c|c|c|}
\hline LA $84,167-170$ & $\mathrm{P}(=\mathrm{BEMV})$ & $I^{1}\left(=I^{2}, 1514\right)$ \\
\hline $\begin{array}{l}\text { Cumque hoc fratribus retulisset, } \\
\text { a ministris Neronis capitur et } \\
\text { prefecto Agrippe presentatur. } \\
\text { Factaque est eius facies sicut sol. } \\
\text { Cui dixit, ut ait Linus: «Tune es } \\
\text { ille [...] }\end{array}$ & $\begin{array}{l}\text { E con él o recomtés als frares, } \\
\text { los ministres d'En Neró lo } \\
\text { preyren e fo liurat al pretor, qui } \\
\text { avia nom Agripe, al qual dix: } \\
\text { «¿No est tu aquel [...] }\end{array}$ & $\begin{array}{l}\text { E, com ell ho recomptàs als } \\
\text { frares, los missatgers d'en Neró } \\
\text { lo prengueren e fonch liurat al } \\
\text { pretor, qui era nomenat Agrip- } \\
\text { pa, e la sua cara fonch feta res- } \\
\text { plandent axí com lo sol, segons } \\
\text { que diu Linus. E dix-li Agrippa: } \\
\text { «No est tu aquell [...] }\end{array}$ \\
\hline
\end{tabular}

Evidentment, la versió d'I ${ }^{1}$ no és completament fidel i presenta lectures errònies (com la de ministris > missatgers), potser degudes a una variant ja existent en el testimoni llatí o a una mala lectura dels incunables. La redacció sintètica dels manuscrits es pot prendre com una evidència de l'abreujament del que fa gala sovint la traducció catalana, ${ }^{25}$ encara que açò no es pot donar com a definitiu sense conéixer la font original emprada per a elaborar la versió en aquesta llengua.

Un altre exemple d'aquesta revisió amb l'objectiu de presentar un text més fidel al que ofereix Varazze, encara que amb variants del tot normals (en aquest cas omissions d'alguns detalls), és el que llegim en el capítol del Naixement de la Mare de Déu:

23. Cal indicar que $\mathrm{I}^{1} \mathrm{i}^{2}$ depenen d'un arquetipus comú, ja que presenten errors separatius entre si que fan que no siga l'un model de l'altre (Càmara 2013: LXI-LXIII).

24. Com a representant dels manuscrits catalans, citem P (editat en Voragine 1977); els fragments d'I ${ }^{1}$ provenen de l'edició de Càmara: 2013.

25. Aquest tret característic ha estat analitzat per Puche en el cas de la vida de santa Maria Magdalena, i arriba a concloure que l'adaptació catalana: «Muestra una marcada tendencia hacia la abreviación y omisión de detalles narrativos, desde la supresión de términos aislados hasta el drástico resumen de largos pasajes latinos» (2012: 186). 


\begin{tabular}{|c|c|c|}
\hline LA $127,66-67$ & P (=BEMV) & $I^{1}\left(=I^{2}, 1514\right)$ \\
\hline $\begin{array}{l}\text { Virgo autem cotidie in omni } \\
\text { sanctitate proficiens et ab angelo } \\
\text { cotidie uisitabatur et uisione } \\
\text { diuina cotidie fruebatur. Ait } \\
\text { autem Ieronimus in quadam } \\
\text { epistola ad Cromatium et } \\
\text { Heliodorum quod beata uirgo } \\
\text { hanc regulam sibi statuerat, ut a } \\
\text { mane usque ad tertiam orationi- } \\
\text { bus insisteret, a tertia usque ad } \\
\text { nonam textrino operi uacaret, a } \\
\text { nona usque uesperas ab oratione } \\
\text { non recedebat quousque angelus } \\
\text { apparens escam sibi dabat. }\end{array}$ & $\begin{array}{l}\text { Enaprés la Verge fo molt per- } \\
\text { feyta en santedat, e era tot dia } \\
\text { visitada per los àngels e usava } \\
\text { tot dia de Déu. }\end{array}$ & $\begin{array}{l}\text { Aprés, la Verge era molt perfeta } \\
\text { en sanctedat, e era tots jorns } \\
\text { visitada per àngels e tots dies } \\
\text { havia de la visió de Déu. Car, } \\
\text { segons que diu sant Hierònim } \\
\text { en una epístola, que la Verge } \\
\text { Maria servava aquesta regla: } \\
\text { que de matí fins a tèrcia fahia } \\
\text { oració, e de tèrcia fins a nona } \\
\text { texia e de nona fins que l'àngel } \\
\text { apparia, qui li portava vianda } \\
\text { per son menjar, tostemps stava } \\
\text { en oració. }\end{array}$ \\
\hline
\end{tabular}

Hem comentat suara (nota 10) que la Legenda aurea presenta dues redaccions d'autor (LA1 i LA2) que, en realitat, suposen dos estadis d'elaboració i reelaboració més o menys continuada, l'inicial i el final. Aquest fet complica la transmissió del llegendari, ja que cal establir a quin grau pertany cada testimoni dins d'aquest procés creatiu. Aquesta característica de l'obra de Varazze afecta també la transmissió del text en les llengües vernacles, ${ }^{26}$ com podem comprovar en aquest exemple de revisió gens comuna que trobem en el capítol de l'Epifania:

\begin{tabular}{|c|c|c|}
\hline LA 14,162 & $\mathrm{P}(=\mathrm{BEMV})$ & $\mathrm{I}^{1}\left(=\mathrm{I}^{2}, 1514\right)$ \\
\hline $\begin{array}{l}\text { LA1: Horum corpora Mediolani } \\
\text { in ecclesia que nunc est ordinis } \\
\text { nostri, scilicet fratrum predica- } \\
\text { torum, quiescebant, sed nunc } \\
\text { Colonie requiescunt. }\end{array}$ & $\begin{array}{l}\text { los corses dels quals solien jazer } \\
\text { a Milà en la esgleya que ara és } \\
\text { de l'orde dels Preÿcadors, mas } \\
\text { arajasen en la ciutat de Colònia }\end{array}$ & \\
\hline $\begin{array}{l}\text { LA2: Nam eorum corpora } \\
\text { primo per Helenam, Cons- } \\
\text { tantini matrem, reperta et in } \\
\text { Constantinopolim translata, } \\
\text { postea per sanctum Eustorgium } \\
\text { Mediolanensem archiepiscopum } \\
\text { perducta, ultimo per Fridericum } \\
\text { imperatorem cum Mediolanum } \\
\text { cepit in ColoniamTheutonie } \\
\text { super Rhenum sunt delata, ubi } \\
\text { in magna reuerentia et populi } \\
\text { deuotione coruscant }\end{array}$ & & $\begin{array}{l}\text { Los cossos d'aquests tres reys, } \\
\text { primerament, per sancta Elena, } \\
\text { mare deConstantí, emperador de } \\
\text { Roma, foren presos e posats en } \\
\text { Constantinòpoli; e, aprés, per } \\
\text { sant Eustòrgio bisbe són trasla- } \\
\text { dats en Milà; e per lo emperado } \\
\text { Henrich,d aprés que hac subju- } \\
\text { gat Milà, foren presos e aportats } \\
\text { en Colònia, sobre lo riu, on fan } \\
\text { grans miracles e són conservats } \\
\text { ab gran honor e reverència. }\end{array}$ \\
\hline
\end{tabular}

26. La filiació del text català que transmeten els incunables del Flos sanctorum amb alguna branca o testimoni de la tradició de la Legenda aurea no és gens facil d'establir per la dificultat que planteja la història textual de l'obra de Varazze. L'única conclusió més segura, en tot cas, és la major fidelitat a l'estadi de redacció que transmet el manuscrit llatí E, cosa que explicaria, en part, la barreja de solucions de la primera i la segona redacció de l'obra que es constata en la traducció (Càmara 2013: LXV-LXVII). 
Aquest tipus de correccions que cerquen una major fidelitat amb la Legenda aurea, són exclusives dels impresos? Aquesta qüestió es planteja quan trobem un fragment com el següent, que pertany al capítol de l'Assumpció:

\begin{tabular}{|l|l|l|}
\hline \multicolumn{1}{|c|}{ LA 115, 6-7 } & \multicolumn{1}{|c|}{ P (=BEV) } & \multicolumn{1}{c|}{$\mathrm{I}^{1}\left(=\mathrm{M}, \mathrm{I}^{2}, 1514\right)$} \\
\hline $\begin{array}{l}\text { Die igitur quadam dum in filii } \\
\text { desiderium cor uirginis uehe- } \\
\text { menter accenditur, estuans ani- } \\
\text { mus commouetur et in exterio- } \\
\text { rem lacrimarum abundantiam } \\
\text { excitatur; cumque ad tempus } \\
\begin{array}{l}\text { subtracti filii equanimiter non } \\
\text { ferret subtracta solacia, angelus } \\
\text { cum multo lumine. }\end{array}\end{array}$ & $\begin{array}{l}\text { Fo un dia que era hac tran } \\
\text { gran desig del seu Fil, perquè } \\
\text { li aparec un àngel ab mot gran } \\
\text { resplandor. }\end{array}$ & $\begin{array}{l}\text { E un dia, axí com fonch vengu- } \\
\text { da de cercar los sanctuaris del } \\
\text { seu fill, li vench tan gran desig } \\
\text { de Jesuchrist que lo seu cor ne } \\
\text { fonch molt mogut a plorar, per } \\
\text { ço com no·s podia més compor- } \\
\text { tar de la companyia del seu fill } \\
\text { Jesuchrist. Per què, encontinent, } \\
\text { li apparegué un àngel molt } \\
\text { resplandent. }\end{array}$ \\
\hline
\end{tabular}

Ara mateix, sense un stemma codicum tancat que establisca la filiació entre els diversos testimonis de la traducció catalana de la Legenda aurea, no podem explicar per què el manuscrit $M$ s'alinea en aquest exemple amb els incunables (encara que amb matisos, ja que omet alguns detalls que sí que apareixen en els impresos). $\mathrm{M}$ consulta esporàdicament una altra versió de la font llatina que, en aquest cas, coincideix amb la solució que dóna el Flos sanctorum romançat? $\mathrm{O}$ entre $\mathrm{M}$ i l'arquetipus d' $\mathrm{I}^{1}$ i $\mathrm{I}^{2}$ hi ha una relació més profunda que els fa pertànyer a la mateixa família o branca? Cap la possibilitat que la revisió del text no siga un fet exclusiu dels incunables? Totes aquestes preguntes només podran tenir resposta si continuem en el camí d'aprofundir en la transmissió i de desenvolupar el treball de col-lació. El que sí que queda clar és el fet que la tradició impresa catalana de la Legenda aurea aporta una revisió del text amb l'objectiu d'oferir una versió més completa i fidedigna.

\section{Conclusions}

La Legenda aurea fou una obra d'una fortuna excepcional entre mitjan segle XIII i el Concili de Trento (1545-1563), moment a partir del qual fou bandejada perquè era massa permissiva en alguns aspectes de la creença i la devoció. Es copià en el llatí original i es difongué ràpidament com una font imprescindible per a la devoció; però també es traduí aviat, com en el cas del català. Aquesta versió, que ens ha pervingut en cinc manuscrits, dos incunables i sis edicions, ajudà a estendre el llegendari entre els cercles laics de la societat de l'època fins que esdevingué una obra devocional de referència, la influència de la qual afectà la literatura, el teatre i l'art.

Entendre la transmissió d'una obra amb tant d'èxit, i amb una extensió gens menyspreable, elaborada en un procés de redacció continuat, és sempre molt complex; però l'estudi que se'n deriva pot ser realment apassionant. En el cas de la traducció catalana, el text arreplegat pels diversos testimonis manuscrits és el 
mateix, amb les aportacions específiques i les variants pròpies de cada còdex. Els incunables també reprodueixen aquesta mateixa versió, però tot introduint-hi algunes modificacions que afectaran el devenir del text.

1) La inclusió de nou capítols que completen el cicle litúrgic amb sants més vinculats al territori o als interessos de qui feia la còpia era un fet del tot normal que permetia l'organització en circulum anni de l'obra de Varazze. En aquest sentit, els incunables n'incorporen catorze de la tradició anterior, però en fan una aportació d'onze, entre els quals es troben sants que sobrepassen el límit cronològic del segle XIII, respectat fins a aquell moment.

2) L'ordre és marcat pel calendari litúrgic cristià i, per tant, no comporta massa innovació. Tant és així que les vides afegides que no se situen en la data de celebració que els correspon passen a formar part d'un suplement posterior a l'últim capítol, dedicat a la consagració de les esglésies. A pesar d'aquesta estructura preestablerta i fixa, els incunables la trenquen de manera sobtada i conscient en alguns capítols, com en el cas de sant Eustaqui, en què s'actualitza la data de la commemoració. Però trobem l'exemple més simptomàtic en la voluntat de completar l'apèndix que Varazze dedica als Pares del desert amb dues vides noves i amb el trasllat d'un conjunt de santes que s'assimilen al model de les Vitae Patrum (que ben bé podríem denominar les Mares del desert).

3) Finalment, la tercera aportació dels incunables a la tradició catalana té a veure amb el contingut. I en aquest cas podem destacar, d'una banda, la substitució del text d'algunes vides, com per exemple la de sant Pau Ermità, en la qual es tradueix directament la font que fa servir Varazze per elaborar el capítol abreujat; i, d'una altra, les revisions que el curador d' $\mathrm{I}^{1}$ i I ${ }^{2}$ aporta a partir de la consulta d'una còpia de la Legenda aurea amb l'objectiu d'ampliar o millorar la versió transmesa pels manuscrits.

Tot plegat confirma la importància dels incunables del Flos sanctorum romançat, dins del procés de difusió en català de l'obra de Iacopo da Varazze, com a pont entre les còpies manuscrites i els impresos cinccentistes: arrepleguen una tradició secular, però aporten un conjunt d'innovacions que transvasen a les edicions posteriors, representades en aquest treball, com hem pogut veure, per la primera, la de 1514. Caldrà estudiar amb més deteniment la consolidació d'aquests canvis en els testimonis que s'estenen al llarg del segle XvI, ja que algunes d'aquestes publicacions presenten al seu torn revisions; però això sobrepassa les intencions de l'article. 


\section{Bibliografia}

Boureau, Alain, La Légende Dorée. Le système narratif de Jacques de Voragine († 1298), París, Les Editions du Cerf, París, 1984.

Càmara-Sempere, Hèctor, El Flos sanctorum romançat. Edició crítica dels dos incunables catalans de la Legenda aurea de Jacobus de Voragine, tesi doctoral inèdita, Alacant, Universitat d'Alacant, 2013.

García Sempere, Marinela, "Algunes dades sobre els manuscrits de la versió catalana de la Legenda aurea», Medievalia, 18/2, 2015, 155-178.

MaGgioni, Giovanni Paolo, Ricerche sulla composizione e sulla transmissione della "Legenda aurea», Florència, Sismel, 1995.

—, «Riletture e rescriture agiografiche del XIII secolo: i leggendari abrreviati», en García Sempere, Marinela, Llorca Tonda, M. Àngels (eds.), Vides medievals de sants: difusió, tradició i llegenda, Alacant, Institut Interuniversitari de Filologia Valenciana, col. "Symposia Philologica», 2012, 11-34.

Puche, Carmen, «La vida de Maria Magdalena en la Legenda Avrea de Iacobvs de Voragine y en Vides de sants rosselloneses: un estudio comparativo", Revista de Filologia Románica, 29, 1, 165-188.

Sabaté, Glòria, Soriano, Lourdes, Avenoza, Gemma (2012), «Vides de sants en manuscrits incomplets i membra disiecta, o com completar el nostre coneixement del que foren les biblioteques antigues», en García Sempere, Marinela, Llorca Tonda, M. Àngels (eds.), Vides medievals de sants: difusió, tradició i llegenda, Alacant, Institut Interuniversitari de Filologia Valenciana, col. «Symposia Philologica», 2012, 33-63.

VARAzZE, Iacopo da, Legenda aurea, edició i traducció a l'italià de Giovanni P. Maggioni, Florència, Edizioni del Galluzzo - Edizione Nazionale dei Testi Mediolatini - Biblioteca Ambrosiana, 2007.

Voràgine, Jaume de, Llegenda àuria, Nolasc Rebull (ed. i intr.), Olot, 1976.

Voragine, Jacobus de, Vides de sants rosselloneses, 3 vols., Ch. S. Maneikis Kniazzeh, E. J., Neugaard i J. Coromines (eds. i intr.), Barcelona, Fundació Salvador Vives Casajuana, 1977. 
